\title{
Development of a nasal spray containing xylometazoline hydrochloride and iota- carrageenan for the symptomatic relief of nasal congestion caused by rhinitis and sinusitis
}

This article was published in the following Dove Press journal: International Journal of General Medicine

\author{
Christine Graf' \\ Andreas Bernkop-Schnürch ${ }^{2}$ \\ Alena Egyed' \\ Christiane Koller \\ Eva Prieschl-Grassauer ${ }^{1}$ \\ Martina Morokutti-Kurz' \\ 'Marinomed Biotech AG, Vienna, \\ Austria; ${ }^{2}$ ThioMatriX, Innsbruck, \\ Austria
}

Introduction: Xylometazoline hydrochloride $(\mathrm{HCl})$ is a nasal decongestant that causes vasoconstriction in the nasal submucosa. It has been used for more than 50 years for the treatment of nasal congestion caused by rhinitis/sinusitis. Iota-carrageenan is effective against a broad variety of respiratory viruses, which are the most common cause of infections of the upper respiratory tract. Therefore, it is used as the active component in the antiviral nasal spray Coldamaris prophylactic $(1.2 \mathrm{mg} / \mathrm{mL}$ iota-carrageenan in $0.5 \% \mathrm{NaCl})$ and other medical device nasal sprays that are approved and marketed in the EU. Recently, we developed a nasal spray formulation containing both xylometazoline $\mathrm{HCl}(0.05 \%)$ and iota-carrageenan $(0.12 \%)$ that provides decongestion and antiviral protection of the nasal mucosa at the same time.

Results: A set of in vitro experiments revealed that the vasoconstrictive properties of xylometazoline $\mathrm{HCl}$ and the antiviral effectiveness of iota-carrageenan against human rhinovirus (hRV) 1a, hRV8 and human coronavirus OC43 were maintained in the formulation containing these two compounds. Permeation experiments using bovine nasal mucosa showed that iotacarrageenan had no significant influence on the permeation of xylometazoline $\mathrm{HCl}$. Finally, in the local tolerance and toxicity study, it was shown that the formulation was well tolerated at the application site with no occurrence of erythema or edema in the nostrils of all rabbits or any signs of toxicity in any of the organs and tissues inspected.

Conclusion: Investigations on compatibility of xylometazoline $\mathrm{HCl}$ and iota-carrageenan demonstrated that the substances do not influence each other, allowing both to fulfill their known specific clinical efficacy (xylometazoline $\mathrm{HCl}$ ) and effectiveness (iota-carrageenan).

Keywords: antiviral, permeation, toxicity, vasoconstriction

\section{Introduction}

Xylometazoline hydrochloride (HCl) (2-[4-(1,1-dimethylethyl)-2,6-dimethylbenzyl]4,5-dihydro- $1 \mathrm{H}$-imidazole $\mathrm{HCl}$ ) is a well-established nasal decongestant that belongs to the pharmacotherapeutic group of sympathomimetic drugs and acts selectively on $\alpha$-adrenergic receptors (alpha-adrenergic agonist). ${ }^{1}$

Xylometazoline $\mathrm{HCl}$ is applied topically to relieve nasal congestion associated with acute or chronic rhinitis, common cold, sinusitis, hay fever or other allergies. It causes vasoconstriction in the nasal submucosa, which is manifested as a collapse of the venous sinusoids. Xylometazoline $\mathrm{HCl}$ action is characterized by a fast onset with an effect obtained after 5-10 minutes and lasting for 6-8 hours. ${ }^{2}$ The efficacy of
Correspondence: Martina

Morokutti-Kurz

Marinomed Biotech AG, Veterinärplatz I,

I210 Vienna, Austria

Tel +43 I 250774460

Fax +43 I 250774493

Email martina.kurz@marinomed.com 
xylometazoline $\mathrm{HCl}$ as a topical nasal decongestant is well proven. ${ }^{3,4}$ Xylometazoline $\mathrm{HCl}$ has been used in the $\mathrm{EU}$ in the treatment of nasal congestion caused by rhinitis/sinusitis since 1959. Since then a large number of preparations containing xylometazoline $\mathrm{HCl}$ have been approved and marketed in several European countries.

Carrageenan is a high-molecular-weight sulfated polymer derived from red seaweed (Rhodophyceae) that has been extensively used in food, cosmetic and pharmaceutical industries, and is generally recognized as safe (GRAS) by the US Food and Drug Administration (FDA), as reviewed by Cohen and Ito. ${ }^{5}$ Three main forms of carrageenans are commercially used: iota-, kappa- and lambda-carrageenan. They differ in the degree of sulfation, solubility and gelling properties. ${ }^{6}$ The antiviral mechanism of carrageenan is based on the interference with viral attachment: carrageenan forms a barrier on the mucosal surface, thereby preventing the interaction between virus and cellular surface. As a result, infection of cells is inhibited. The antiviral effectiveness varies with the type of polymer as well as the virus and the host cells, ${ }^{7-17}$ as reviewed previously. ${ }^{18-20}$ We already published that iota-carrageenan is a potent inhibitor of major (intercellular adhesion molecule 1 receptor) and minor group (low-density lipoprotein receptor) human rhinovirus (hRV) ${ }^{21}$ and influenza virus A replication. ${ }^{22}$ Furthermore, we demonstrated the broad antiviral efficacy of an iota-carrageenan containing nasal spray against common cold viruses in several randomized, double-blind, parallel-group, placebo-controlled clinical trials. $^{23-25}$ The pooled analysis of two studies conducted in 153 children and 203 adults revealed that patients infected with any respiratory virus who were intranasally treated with iota-carrageenan showed a 1.9-day faster recovery from common cold symptoms than placebo-treated patients in the intention-to-treat population. ${ }^{26}$ Carrageenan is contained in medical device nasal sprays that have been approved and marketed in the EU for 10 years for the supportive treatment of common cold/flu-like illnesses caused by viruses.

The rationale for merging xylometazoline $\mathrm{HCl}$ with iotacarrageenan into one product is based on the intent to combine their properties, namely the decongestant efficacy provided by xylometazoline $\mathrm{HCl}$ and the effectiveness to reduce viral infection accomplished by iota-carrageenan. The intranasal (i.n.) topical application provides reliable and fast relief from the symptoms of nasal congestion and facilitates breathing during common cold/flu-like illnesses and allergic rhinitis. Furthermore, it facilitates drainage of the secretion during sinusitis and can be used as an adjuvant treatment of mucosal swelling due to otitis media. Additionally, iota-carrageenan can reduce the reproduction and spreading of respiratory viruses. The above described indications frequently involve viral infections which worsen the course of the underlying disesase. Therefore, a nasal spray which combines decongestant and antiviral properties is benefitial for patients when compared to conventional xylometazoline $\mathrm{HCl}$ products.

Therefore, a medicinal product containing xylometazoline $\mathrm{HCl}$ and iota-carrageenan for the proposed indication and route of administration is advantageous and reasonable from a scientific and a medicinal point of view. In order to evaluate whether the properties of xylometazoline $\mathrm{HCl}$ are affected by the presence of iota-carrageenan, a set of experiments was performed.

\section{Materials and methods}

All repeated dose toxicity studies were performed in accordance with Good Laboratory Practice (GLP) requirements as outlined in the OECD Principles of GLP (revised in 1997). These studies were also performed according to ISO 10993 "Biological evaluation of medical devices" and according to current European and OECD guidance for testing pharmaceuticals for human use (see citation for each study). It is emphasized that all animal studies presented in this manuscript were pivotal studies in a nonclinical program for pharmaceutical drug development and were therefore compliant with OECD Principles of GLP and national GLP requirements. For all animal studies, procedures and facilities comply with requirements of commission directive 86/609/ $\mathrm{EEC}$ and national legislation defined in animal protection law concerning the protection of animals used for experimental and other scientific procedures. All animals were bred for experimental purposes according to Art. 9.2, No. 7 of the German Act on Animal Welfare. The studies were conducted by BSL BIOSERVICE GmbH (Munich, Germany) to comply with OECD principles of GLP and the German Acts on Animal Welfare (Tierschutzgesetz, July 2009). The studies were authorized under the BSL BIOSERVICE licenses to conduct repeated dose toxicity studies granted by the government of Upper Bavaria, Munich, Germany. Approval was received before the start of the studies from the competent authority: Regierung von Oberbayern, Abteilung Veterinärwesen (80534 Munich, Germany). Animal housing and handling including sacrifice fulfilled standard requirements for pivotal GLP studies to be used in the nonclinical development of pharmaceuticals. Studies followed ICH M3 guidance and are therefore also in accordance with the $3 \mathrm{R}$ (replacement, reduction, refinement) principles for more ethical use of animals in testing. In all studies, to alleviate animal suffering on the day of sacrifice 
animals were anesthetized either by an intramuscular injection of ketamine/xylazine or ketamine/medetomidine or/and by an intraperitoneal injection of thiopental, and the euthanasia was made by exsanguination. Studies were conducted at professional contract research organizations specialized on nonclinical testing of drug candidates.

\section{Test solutions}

The following test solutions (Table 1) were used in the experiments described in the methods section.

Table I Test solutions

\begin{tabular}{|c|c|c|}
\hline Test solution & Ingredient & $\mathrm{mg} / \mathrm{mL}$ \\
\hline \multirow[t]{7}{*}{ Base formulation } & Sodium chloride & 5.0 \\
\hline & Disodium hydrogen & 11.26 \\
\hline & phosphate dihydrate & \\
\hline & Citric acid monohydrate & 3.87 \\
\hline & Disodium edetate & 1.0 \\
\hline & dihydrate & \\
\hline & Purified water & Ad I mL \\
\hline \multirow[t]{2}{*}{ Xylo_0.05\% } & Base formulation & \\
\hline & Xylometazoline $\mathrm{HCl}$ & 0.5 \\
\hline \multirow[t]{2}{*}{ Carr_0.12\% } & Base formulation & \\
\hline & lota-carrageenan & 1.2 \\
\hline \multirow[t]{3}{*}{ Xylo_0.05\%/Carr_0.12\% } & Base formulation & \\
\hline & lota-carrageenan & 1.2 \\
\hline & Xylometazoline $\mathrm{HCl}$ & 0.5 \\
\hline \multirow[t]{2}{*}{ Carr_0.12\% in $0.5 \% \mathrm{NaCl}$} & $\mathrm{NaCl}$ & 5.0 \\
\hline & lota-carrageenan & 1.2 \\
\hline
\end{tabular}

\section{Cells and viruses}

Human rhinoviruses la and 8 (hRVIa and hRV8)

The human cervical epithelial carcinoma cell line (HeLa) was obtained from the American Type Culture Collection (ATCC, Manassas, VA, USA). The cells were cultivated in Dulbecco's minimal essential medium (Sigma-Aldrich, Vienna, Austria) supplemented with 10\% fetal bovine serum (Sigma-Aldrich) and $1 \%$ antibiotic-antimycotic mix (Sigma-Aldrich) in an incubator at $37^{\circ} \mathrm{C}$ (Sanyo, Okayama Prefecture, Japan; $\mathrm{CO}_{2}$ : $5 \%$, relative humidity: $>95 \%$ ). During virus infection and viral experiments, a medium containing $2 \%$ fetal bovine serum and $1 \%$ antibiotic-antimycotic mix was used. HRV1a and 8 serotypes were obtained from ATCC and grown on HeLa cells. The stocks were frozen at $-80^{\circ} \mathrm{C}$, and virus titers were determined by $50 \%$ tissue culture infective dose $\left(\mathrm{TCID}_{50}\right)$ assay.

\section{Human coronavirus OC43 (hCoV OC43)}

Vero (embryonic African green monkey kidney) cells were purchased from ATCC. The cells were cultivated in OptiPro serum-free medium (Life Technologies, Thermo Fisher
Scientific, Waltham, MA, USA) supplemented with $4 \mathrm{mM}$ L-glutamine (Sigma-Aldrich) in an incubator at $37^{\circ} \mathrm{C}\left(\mathrm{CO}_{2}\right.$ : $5 \%$, relative humidity: $>95 \%$ ). $\mathrm{HCoV}$ OC43 was obtained from ATCC and propagated in the same medium. The stocks were frozen at $-80^{\circ} \mathrm{C}$, and virus titer was determined by $\mathrm{TCID}_{50}$ assay.

\section{Methods}

Cytopathic effect reduction assay - hRVIa and hRV8

The assay was performed as described elsewhere. ${ }^{27}$ In brief, a dilution series of Xylo_0.05\%/Carr_0.12\%,Carr_0.12\% and the assay reference Carr_0.12\% in $0.5 \% \mathrm{NaCl}$ was prepared in the base formulation and $0.5 \% \mathrm{NaCl}$, respectively. First, the virus was pre-incubated with the dilution series of test samples and controls for 10 minutes. After an infection period of 30 minutes, cells were washed and further cultivated in the presence of the test samples at the same concentrations as used during the virus pre-incubation period. An incubation of cells with the same dilution series in the absence of viral infection was performed to monitor a potential toxicity of the treatment. The antiviral activity of the sample dilutions was assessed after 42 (hRV8) or 48 hours (hRV1a) of culture by determining the viability of HeLa cells normalized to toxicity data and non-infected control. With the highest iotacarrageenan dose of $40 \mu \mathrm{g} / \mathrm{mL}$, a maximal xylometazoline $\mathrm{HCl}$ concentration of $16.7 \mu \mathrm{g} / \mathrm{mL}$ was obtained, which was well tolerated by the cells. To enable a comparison of the antiviral effectiveness of the test solutions, the half maximal inhibitory concentration $\left(\mathrm{IC}_{50}\right)$ of each sample was calculated for a sigmoidal dose-response model with XLfit Excel addin version 5.3.1.

\section{Hemagglutination inhibition ( $\mathrm{HAI}$ ) assay $-\mathrm{hCoV}$ OC43}

The assay was performed as described elsewhere. ${ }^{27}$ In brief, the virus was pre-incubated with a dilution series of the test items for 10 minutes at room temperature before a suspension of chicken red blood cells (RBCs) was added. After incubation at $4^{\circ} \mathrm{C}$ for 1.5 hours, the plates were photographed and evaluated. Positive control RBCs in the absence of the test sample were fully agglutinated by the virus, whereas inhibition of hemagglutination was observed in wells containing a sufficient amount of iota-carrageenan to inhibit virus binding to RBCs. The minimal inhibitory concentration of each sample to maintain RBC mobility was noted for comparison of the antiviral efficacy of each sample under these assay conditions. Results were compared to a reference sample with known inhibitory activity. 


\section{Hen's egg test on the chorioallantoic membrane (HET-CAM)}

Prior to use, fertilized eggs (Lohmann Selected Leghorn; Schropper GmbH, Vienna, Austria) were placed in a motor-driven egg incubator in a humidified atmosphere at $37.5^{\circ} \mathrm{C}$ to start embryonic development. On embryo development day (EDD), 5 eggs were rotated and stored with blunt end up. On EDD 6, 1-1.5 mL of albumen was extracted from a punctured hole near the pointed end of the egg, which was afterward sealed with molten wax. The CAM was accessed at the blunt end by removal of eggshell and outer membranes with sterile forceps, and then the opening was sealed with an adhesive tape. Eggs were incubated at $37.5^{\circ} \mathrm{C}$ in an egg incubator and checked daily for viability and/or infection. On EDD 10, the CAM was photographed before ( 0 minutes) and 15 and 30 minutes after application of $300 \mu \mathrm{L}$ of the test sample. Digital images were used to measure the diameter of the blood vessels with ImageJ software.

\section{Permeation studies utilizing bovine respiratory mucosa of the nasal cavity}

The study was performed by ThioMatriX GmbH (Innsbruck, Austria) with the test solutions described in Table 1. Tissue samples with a size of $3-4 \mathrm{~cm}^{2}$ of freshly excised bovine respiratory mucosa of the nasal cavity, which was obtained from a local slaughterhouse (Landmetzgerei Piegger KG, Sistrans, Austria), were inserted in Ussing-type chambers displaying a permeation area of $0.64 \mathrm{~cm}^{2} .^{28}$ The apical side of the tissue was therefore facing the donor compartment. Preheated $\left(37^{\circ} \mathrm{C}\right)$ permeation medium containing 0.492 $\mathrm{mM} \mathrm{MgCl}_{2} * 6 \mathrm{H}_{2} \mathrm{O}, 4.56 \mathrm{mM} \mathrm{KCl}, 119.8 \mathrm{mM} \mathrm{NaCl}, 15 \mathrm{mM}$ $\mathrm{NaHCO}_{3}, 10 \mathrm{mM}$ D-glucose and $50 \mathrm{mM}$ HEPES buffer $\mathrm{pH}$ 7.2 was added to the donor and acceptor chamber. After a pre-incubation time of 15 minutes, the permeation medium in the donor chamber was substituted by mixtures of 500 $\mu \mathrm{L}$ buffer and $500 \mu \mathrm{L}$ xylometazoline $\mathrm{HCl}$ test samples with and without iota-carrageenan (Xylo_0.05\% Carr_0.12\%, Xylo_0.05\%). Fluorescein isothiocyanate-labeled dextran $500 \mathrm{kDa}(\mathrm{FD}-500)$ or sodium fluorescein (Na-Flu) in final concentrations of $0.01 \%$ or $0.001 \%(\mathrm{~m} / \mathrm{v})$, respectively, served as controls. Over a time period of 180 minutes, aliquots of $2 \times 110 \mu \mathrm{L}$ were withdrawn from the acceptor compartment every 60 minutes and immediately replaced by $220 \mu \mathrm{L}$ permeation medium preheated at $37^{\circ} \mathrm{C}$. Concentration of fluorescence markers in withdrawn aliquots was determined as already described. Additionally, the integrity of the bovine nasal mucosa was proven by transepithelial electrical resistance measurements. All studies and tests were carried out in fivefold at least. Statistical data analysis was performed using one-way ANOVA following StudentNewman-Keuls test with $p<0.05$ as the minimal level of significance.

\section{2-Week local tolerance and toxicity study in rabbits}

The local tolerance study was performed with three treatment groups including two dose groups and one control group. The three groups comprised three male and three female New Zealand white rabbits. Each animal received repeated i.n. applications of the test item or the control into the left nostril. The untreated right nostril served as negative control. The dosage of both test item groups and the control group was $140 \mu \mathrm{L}$ per application, $420 \mu \mathrm{L}$ per day (three applications per day). The dosage of the Xylo_0.05\%/ Carr_0.12\% formulation contained $168 \mu \mathrm{g}$ iota-carrageenan per application corresponding to $504 \mu \mathrm{g}$ daily dose and $70 \mu \mathrm{g}$ xylometazoline $\mathrm{HCl}$ per application corresponding to $210 \mu \mathrm{g}$ daily dose. The dosage of Xylo_0.05\% contained the same amount of xylometazoline $\mathrm{HCl}$ but no iota-carrageenan. The control comprised the base formulation as described in Table 1. Before each application, the nostrils were observed for signs of irritation or edema or any other reaction, according to a defined classification system (Draize scoring). The nostrils were examined with an otoscope before the beginning of the treatment period and on day 15 . The animals were weighed prior to the first application and then a week thereafter. Clinical biochemistry and hematology parameters were determined prior to the first treatment and at the end of the treatment period. At the end of the study, all animals were sacrificed and subjected to a gross necropsy. The wet weight of a set of tissues was taken, and a set of organs/tissues was preserved. A full histopathology was carried out only on nasal cavities (including turbinates, left and right nostrils), brain (including bulbus olfactorius, medulla/pons cerebellar and cerebral cortex) and all organs with macroscopic findings of all study animals. A statistical assessment was performed for each sex by comparing the values of treated with control animals using a one-way ANOVA and a post hoc Dunnett's test. The statistics was performed with GraphPad Prism V.6.01 software or E-Workbook software $(p<0.5)$. This study was performed in the test facility of BSL BIOSERVICE Scientific Laboratories GmbH (Planegg, Germany) and was conducted in compliance with the Committee for Medicinal Products for Human Use (CHMP) note for guidance on repeated dose toxicity (EMEA/CHMP/SWP/1042/99 corr, July 27, 2000). 


\section{Results}

\section{Xylometazoline $\mathrm{HCl}$ does not affect the} antiviral effectiveness of iota-carrageenan

Standardized assays, namely a cell-based assay using the HeLa cells and a HAI assay, were employed to determine the antiviral activity of iota-carrageenan in the presence and absence of xylometazoline $\mathrm{HCl}$ against non-enveloped hRV1a (minor group) and hRV8 (major group) and against the enveloped hCoV OC43, respectively. Both assays have already been described elsewhere ${ }^{21,27}$ and are outlined in brief in the "Materials and methods" section. Test solutions are described in Table 1.

Antiviral effectiveness of iota-carrageenan in the presence and absence of $0.05 \%$ xylometazoline $\mathrm{HCl}$ against $h R V l a$ and $h R V 8$

The effectiveness of Carr_0.12\%/Xylo_0.05\% to inhibit the replication of hRV1a and hRV8 (Table 2) was tested in comparison with Carr_0.012\% and Carr_0.012\% in 0.5\% $\mathrm{NaCl}$ as a reference. With the highest tested iota-carrageenan concentration of $40 \mu \mathrm{g} / \mathrm{mL}$, a maximal xylometazoline $\mathrm{HCl}$

Table 2 Antiviral effectiveness of iota-carrageenan formulations against hRVIa and hRV8

\begin{tabular}{ll}
\hline Effectiveness against hRV Ia & IC $_{50} \pm 95 \% \mathbf{C l}(\mu \mathrm{g} / \mathrm{mL})$ \\
\hline Carr_0.I2\%/Xylo_0.05\% & $6.2 \pm 2.48$ \\
Carr_0.12\% & $16.5 \pm 10.19$ \\
Carr_0.12\% in 0.5\% NaCl & $7.3 \pm 2.53$ \\
\hline Effectiveness against hRV8 & $\mathrm{IC}_{50} \pm 95 \% \mathrm{Cl}(\mu \mathrm{g} / \mathrm{mL})$ \\
\hline Carr_0.12\%/Xylo_0.05\% & $1.65 \pm 0.36$ \\
Carr_0.12\% & $1.66 \pm 0.91$ \\
Carr_0.12\% in $0.5 \% \mathrm{NaCl}$ & $1.12 \pm 0.44$ \\
\hline
\end{tabular}

Notes: $\mathrm{IC}_{50}$ values of the test solutions and lower and upper $95 \% \mathrm{Cl}$ values were calculated for a sigmoidal dose-response model with XLfit Excel add-in version 5.3. I. Abbreviations: $h R V$, human rhinovirus; $I_{50}$, half maximal inhibitory concentration; $\mathrm{Cl}$, confidence interval.

concentration of $16.7 \mu \mathrm{g} / \mathrm{mL}$ was obtained, which was still well tolerated by the cells. As expected, all iota-carrageenancontaining solutions showed a comparable antiviral effectiveness, as shown by their $\mathrm{IC}_{50}$ values and their overlapping confidence intervals (Table 2).

\section{Antiviral effectiveness of iota-carrageenan in the presence and absence of $0.05 \%$ xylometazoline $\mathrm{HCl}$ against hCoV OC43}

The ability of hCoV OC43 to agglutinate chicken erythrocytes can be dose dependently inhibited by iota-carrageenan. This is utilized in the HAI assay to evaluate the antiviral efficacy of iota-carrageenan-containing test samples in
Table 3 Antiviral effectiveness of iota-carrageenan formulations against hCoV OC43

\begin{tabular}{ll}
\hline Test solution & MIC $(\mu \mathrm{g} / \mathrm{mL})$ \\
\hline Carr_0.12\%/Xylo_0.05\% & 0.024 \\
Carr_0.12\% & 0.024 \\
Carr_0.12\% in $0.5 \% \mathrm{NaCl}$ & 0.024 \\
\hline
\end{tabular}

Note: The MIC at which the test solutions still exhibit the antiviral activity is given. Abbreviations: hCoV OC43, human coronavirus OC43; MIC, minimal inhibitory concentration.

comparison with a reference sample of known inhibitory activity as described elsewhere. ${ }^{27}$ Here, we tested the ability of Carr_0.12\%/Xylo_0.05\% to inhibit the hemagglutination of erythrocytes by hCoV OC43 in comparison with Carr_0.12\% and Carr_0.12\% in $0.5 \% \mathrm{NaCl}$ as a reference. For a description of the test solutions see Table 1. With the highest tested iota-carrageenan concentration of $3 \mu \mathrm{g} / \mathrm{mL}$, a maximal xylometazoline $\mathrm{HCl}$ concentration of $1.25 \mu \mathrm{g} / \mathrm{mL}$ was obtained, which was still well tolerated by the erythrocytes. All iotacarrageenan-containing solutions showed the same antiviral effectiveness, namely a MIC of $0.024 \mu \mathrm{g} / \mathrm{mL}$ (Table 3).

In conclusion, we confirmed that iota-carrageenan retains its antiviral effectiveness in the presence of xylometazoline $\mathrm{HCl}$.

\section{lota-carrageenan does not affect the vasoconstrictive efficacy of xylometazoline $\mathrm{HCl}$}

The CAM is a highly vascularized membrane that surrounds the developing chicken embryo. The HET-CAM is a sensitive, cheap and easily feasible test to investigate potential antiinflammatory compounds and extracts, and is widely used to assess the irritation potential of test substances. ${ }^{29,30}$ It was first described by Luepke. ${ }^{31}$ According to the original test method, fertilized hen's eggs are incubated under optimized conditions for 9 days. On the 10th day, the eggs are opened and the CAM is exposed. Then, $0.3 \mathrm{~mL}$ of the test substance is applied to the surface of the CAM. After a defined exposure period, the CAM is evaluated for development of irritant endpoints (hyperemia, hemorrhage and coagulation). Effects in the CAM blood vessels and albumen are subjectively assessed and scored. By now, several alternative parameters like lysis, hyperemia and vasoconstriction have been evaluated using adapted HET-CAM protocols. ${ }^{32}$

Here, we used an adapted HET-CAM protocol to test the vasoconstrictive potential of xylometazoline $\mathrm{HCl}$ in the presence and absence of iota-carrageenan. The CAM is photographed before and 15 and 30 minutes after the application of the test sample. As shown in Table 4, the vasoconstrictive effectiveness of the combination product Xylo_0.05\%/Carr_0.12\% 
Table 4 Vasoconstrictive efficacy of $0.05 \%$ xylometazoline $\mathrm{HCl}$ in the presence and absence of $0.12 \%$ iota-carrageenan

\begin{tabular}{llll}
\hline Test solution & $\begin{array}{l}\text { Time after } \\
\text { application } \\
\text { [minutes] }\end{array}$ & $\begin{array}{l}\text { Mean vessel } \\
\text { diameter [\%] } \\
\text { (SD) [\%] }\end{array}$ & Before application \\
\hline Xylo_0.05\%/Carr_0.12\% $(\mathrm{n}=4)$ & $\mathbf{0}$ & 100 \\
\hline 15 & $86.5(6.2)$ \\
& 30 & $83.9(7.2)$ \\
\hline Xylo_0.05\% $(\mathrm{n}=3)$ & 0 & 100 \\
\hline 30 & $81.3(4.6)$ & \\
\hline
\end{tabular}

Notes: The assay was performed on EDD 10. The CAM was photographed before and in a time course of 15 and 30 minutes after the application of $300 \mu \mathrm{L}$ test sample Xylo_0.05\%/Carr_0.12\% and Xylo_0.05\%. Digital images were used to measure blood vessel diameters with ImageJ software. The results are shown as the mean vessel diameter as the percentage of the initial diameter \pm SD of the indicated number of samples per group and are representative of one single experiment. On the right, pictures of the blood vessels before and 30 minutes after application of the respective test item are shown.

Abbreviations: EDD, embryo development day; CAM, chorioallantoic membrane; SD, standard deviation; $n$, number of samples per group.

(reduction to $83.9 \%$ of the initial vessel diameter) is comparable to the effectiveness of the single compound Xylo_ $0.05 \%$ (reduction to $79.3 \%$ of the initial vessel diameter). The overlap of the $95 \%$ confidence intervals for the mean diameter of the samples indicates that the difference is not significant and that the vasoconstriction mediated by xylometazoline $\mathrm{HCl}$ is preserved in the presence of iota-carrageenan.

\section{lota-carrageenan does not affect the permeation behavior of xylometazoline $\mathrm{HCl}$}

An ex vivo mucosal permeation study was performed to investigate the impact of iota-carrageenan on the permeation ability of xylometazoline $\mathrm{HCl}$. To this end, the permeation of xylometazoline $\mathrm{HCl}$ in the presence (Xylo_0.05\%/Carr_0.12\%) or absence of iota-carrageenan (Xylo_0.05\%) was evaluated on freshly excised bovine nasal mucosa. Na-Flu was used as the positive control, and fluorescein-labeled dextran with a molecular mass of $500 \mathrm{kDa}$ (FD-500) was used as the negative control.

Results of the permeation experiments (Table 5) displayed a comparatively high permeation of Na-Flu with $7.23 \% \pm$ $1.03 \%$. By contrast, only $0.71 \% \pm 0.15 \%$ of FD- 500 passed the nasal mucosa. Furthermore, within 3 hours, a permeation of $8.19 \% \pm 3.61 \%$ was determined for Xylo_0.05\%/Carr_0.12\%. For comparison, $11.72 \% \pm 1.42 \%$ of xylometazoline $\mathrm{HCl}$ without iota-carrageenan (Xylo_0.05\%) permeated the tis-
Table 5 Comparison of permeated percentage amounts for indicated test formulations across bovine nasal mucosa

\begin{tabular}{ll}
\hline Test solution & $\begin{array}{l}\text { Permeated } \\
\text { Xylometazoline } \mathbf{H C l} \text { (\%) }\end{array}$ \\
\hline Na-Flu (positive control) & $7.23 \pm 1.03$ \\
FD-500 (negative control, $500 \mathrm{kDa})$ & $0.71 \pm 0.15$ \\
Xylo_0.05\%/Carr_0.12\% & $8.19 \pm 3.61$ \\
Xylo_0.05\% & $11.72 \pm 1.42$ \\
\hline
\end{tabular}

Notes: Permeation through mucosa (from apical to basolateral) was measured using Ussing-type chambers followed by HPLC analysis. After 180 minutes, samples from apical and basolateral buffer reservoirs were collected, and xylometazoline $\mathrm{HCl}$ was quantified. Indicated values are means $\pm \mathrm{SD}$ of five experiments.

Abbreviations: $\mathrm{HCl}$, hydrochloride; Na-Flu, sodium fluorescein; FD-500; fluorescein isothiocyanate-labeled dextran $500 \mathrm{kDa}$; SD, standard deviation.

sue, indicating that the transport of xylometazoline $\mathrm{HCl}$ is not significantly impaired in the presence of iota-carrageen an as shown by the overlap of confidence intervals.

\section{The Xylo_0.05\%/Carr_0.12\% nasal spray is well tolerated upon repeated intranasal administration - study on local tolerance and toxicity}

We conducted an i.n. local tolerance and toxicity study with Xylo_0.05\%/Carr_0.12\% and Xylo_0.05\% compared with the base formulation as control (Table 1). The purpose of this study was to obtain information on the tolerability of Xylo_0.05\%/Carr_0.12\% in rabbits after repeated i.n. 
administration over a period of 14 days. Xylo_0.05\%/ Carr_0.12\% was applied three times/day at a dose/application of $70 \mu \mathrm{g}$ xylometazoline $\mathrm{HCl}$ and $168 \mu \mathrm{g}$ iota-carrageenan; application of Xylo_ $0.05 \%$ delivered the same dose of xylometazoline $\mathrm{HCl}$ but $0 \mu \mathrm{g}$ of iota-carrageenan. No mortality occurred in the control or any of the dose groups during the treatment period of this study; a three-time daily administration of neither Xylo_0.05\%/Carr_0.12\% nor Xylo_0.05\% was associated with any clinical symptoms in male or female rabbits. At the application site, the test solutions were well tolerated. Throughout the study, neither erythema nor edema were observed at the nostrils of all animals; there was no effect on body weight or on hematological parameters. No treatment-related effect on clinical biochemistry is assumed after treatment with Xylo_0.05\%/Carr_0.12\% or Xylo_0.05\%. Changes in single parameters, e.g., alanineaminotransferase, aspartate-aminotransferase or glutamate dehydrogenase, were observed in single animals treated with Xylo_0.05\%/Carr_0.12\%. However, these changes were not severe and were not considered of toxicological relevance, when comparing to minimum/maximum ranges of the control, historical data and/or pretreatment values. In addition, no correlation with other parameters (e.g., histopathology) was determined for the aforementioned findings. No gross pathological abnormalities or abnormal organ weights of toxicological concern were found in animals treated with Xylo_0.05\%/Carr_0.12\% or Xylo_0.05\%. After treatment with Xylo_0.05\%/Carr_0.12\%, a slightly higher thymus, epididymides, prostate and ovary weight was found. Slightly but not significantly higher weight of thymus, spleen, ovaries and epididymides was also associated with treatment with Xylo_0.05\%. However, relative organ weights did not exceed values of respective historical controls.

In conclusion, Xylo_0.05\%/Carr_0.12\% was well tolerated at the application site with no occurrence of erythema or edema at the nostrils of all animals or any signs of toxicity at the daily dose tested. Xylo_0.05\%/Carr_0.12\% did not produce any morphological indicators for toxicity in any of the organs and tissues examined. No test item-related changes on clinical biochemistry parameters and relative organ weights were detected in this study.

\section{Discussion}

Carrageenan has been extensively used in food, cosmetic and pharmaceutical industries, and is on the FDA's list of generally recognized as safe (GRAS) products for consumption (21 CFR 172.620). We demonstrated the antiviral effectiveness of iota-carrageenan against a variety of respiratory viruses in several preclinical and clinical trials; $;{ }^{21-26}$ therefore, it has been approved for marketing in the EU, Asia and Australia as part of a variety of over-the-counter products addressing common cold and related diseases.

Iota-carrageenan is effective against a wide range of viruses, enveloped (herpes simplex viruses 1 and 2, human cytomegalovirus, vesicular stomatitis virus, Sindbis virus, influenza virus and human immunodeficiency virus ${ }^{9,13,18-20,22}$ ) and non-enveloped ( $\mathrm{hRV},{ }^{21}$ human papillomavirus ${ }^{10}$ ) ones, with a vast number of different viral and cellular receptor molecules involved in the infection process. ${ }^{33}$ This rules out a specific interaction of iota-carrageenan with viral attachment proteins and demonstrates that its mode of action is unspecific and solely physical. Based on these considerations, we propose that the antiviral activity of carrageenan is based on a two-step-mechanism: first, iota-carrageenan forms a viscous layer at the mucosa, in which virus particles entering the nasal cavity become trapped. Therefore, they cannot infect mucosal cells; primary infection is prevented. Second, newly synthesized virus particles that are excreted from the cells adhere to the carrageenan film as well, resulting in an inhibition of secondary infection. This leads to a significant reduction of viral load in the nasal fluid and hence a reduction of duration of disease. ${ }^{23-26}$ This mechanistic scenario is further supported by permeation experiments as described by Hebar et $\mathrm{al}^{34}$ in which the permeation behavior of methyl anthranoyl-labeled iota-carrageenan on bovine nasal mucosa was evaluated at pH 7.5 (healthy nasal mucosa) and pH 5.5 (infected nasal mucosa). No permeation was observed at both $\mathrm{pH}$ values over a period of 3 hours, indicating that carrageenan was still present on the surface as a film. We then wanted to know how long carrageenan stays in the nasal mucosa before it is removed by the mucociliary clearance system. To this end, we performed an adapted saccharin test, which was first described by Andersen et $\mathrm{l}^{35}$ in 1974 to evaluate the time to taste clearance in the presence and absence of $0.18 \%$ iotacarrageenan. We conducted a cross-over study in which the nasal mucociliary clearance (NMC) time was determined in 5 healthy volunteers (4 females, 1 male; age 32-59 years) in a double blinded setup. To this end, two nasal spray formulations containing glycyrrhizin as a taste marker with and without $0.18 \%$ iota-carrageenan were prepared and blinded. $140 \mu \mathrm{L}$ of test formulation were applied into each nostril; the time of application, the first detection of taste and the time of absence of taste were noted. From these data, NMC mean values $( \pm$ SD) were calculated for both groups. The mean NMC time was $127( \pm 43)$ minutes in the carrageenan-free group; when carrageenan was present, NMC was extended 
by $100.78 \%$ to 255.8 ( \pm 163.38$)$ minutes. From these data, we conclude that carrageenan forms a protective layer on the mucosa, which stays for about 4 hours. During this time, the mucosa is protected from viral infection.

Importantly, the results presented in this paper demonstrate that the carrageenan barrier does not influence the permeation behavior, toxicity and safety profile or the vasoconstrictive efficacy of xylometazoline $\mathrm{HCl}$, while its antiviral effectiveness remains unchanged.

\section{Conclusion}

A nasal spray containing xylometazoline $\mathrm{HCl}$ and iotacarrageenan for the treatment or adjuvant treatment of common cold, sinusitis, rhinitis or otitis media is advantageous and reasonable from a scientific and medicinal point of view. Investigations on the compatibility of xylometazoline $\mathrm{HCl}$ and iota-carrageenan demonstrated that iota-carrageenan does not impair the efficacy and safety of xylometazoline $\mathrm{HCl}$ and vice versa.

\section{Disclosure}

ThioMatriX $\mathrm{GmbH}$, as a contract research organization to Marinomed Biotech AG, had a role in study design, data collection and analysis. All authors except Andreas Bernkop-Schnürch (ThioMatriX GmbH) are employees of Marinomed Biotech AG. Author Eva Prieschl-Grassauer is the co-founder of Marinomed Biotech AG and inventor on patent WO200806792 that relates to the content of the manuscript. The authors report no other conflicts of interest in this work.

\section{References}

1. Haenisch B, Walstab J, Herberhold S, et al. Alpha-adrenoceptor agonistic activity of oxymetazoline and xylometazoline. Fundam Clin Pharmacol. 2010;24(6):729-739.

2. Hamilton LH. Effect of xylometazoline nasal spray on nasal conductance in subjects with coryza. J Otolaryngol. 1981;10(2):109-116.

3. Williams RG, Eccles R. Nasal airflow asymmetry and the effects of a topical nasal decongestant. Rhinology. 1992;30(4):277-282.

4. Castellano F, Mautone G. Decongestant activity of a new formulation of xylometazoline nasal spray: a double-blind, randomized versus placebo and reference drugs controlled, dose-effect study. Drugs Exp Clin Res. 2002;28(1):27-35.

5. Cohen SM, Ito N. A critical review of the toxicological effects of carrageenan and processed eucheuma seaweed on the gastrointestinal tract. Crit Rev Toxicol. 2002;32(5):413-444.

6. Michel G, Nyval-Collen P, Barbeyron T, Czjzek M, Helbert W. Bioconversion of red seaweed galactans: a focus on bacterial agarases and carrageenases. Appl Microbiol Biotechnol. 2006;71(1):23-33.

7. Carlucci MJ, Ciancia M, Matulewicz MC, Cerezo AS, Damonte EB. Antiherpetic activity and mode of action of natural carrageenans of diverse structural types. Antiviral Res. 1999;43(2):93-102.

8. Talarico LB, Damonte EB. Interference in dengue virus adsorption and uncoating by carrageenans. Virology. 2007;363(2):473-485.
9. González ME, Alarcón B, Carrasco L. Polysaccharides as antiviral agents: antiviral activity of carrageenan. Antimicrob Agents Chemother. 1987;31(9):1388-1393.

10. Buck CB, Thompson CD, Roberts JN, Müller M, Lowy DR, Schiller JT. Carrageenan is a potent inhibitor of papillomavirus infection. PLoS Pathog. 2006;2(7):e69.

11. Carlucci MJ, Scolaro LA, Noseda MD, Cerezo AS, Damonte EB. Protective effect of a natural carrageenan on genital herpes simplex virus infection in mice. Antiviral Res. 2004;64(2):137-141.

12. Pujol CA, Scolaro LA, Ciancia M, Matulewicz MC, Cerezo AS, Damonte EB. Antiviral activity of a carrageenan from Gigartina skottsbergii against intraperitoneal murine herpes simplex virus infection. Planta Med. 2006;72(2):121-125.

13. Baba M, Snoeck R, Pauwels R, de Clercq E. Sulfated polysaccharides are potent and selective inhibitors of various enveloped viruses, including herpes simplex virus, cytomegalovirus, vesicular stomatitis virus, and human immunodeficiency virus. Antimicrob Agents Chemother. 1988;32(11):1742-1745.

14. Talarico LB, Pujol CA, Zibetti RG, et al. The antiviral activity of sulfated polysaccharides against dengue virus is dependent on virus serotype and host cell. Antiviral Res. 2005;66(2-3):103-110.

15. Turville SG, Aravantinou M, Miller T, et al. Efficacy of Carraguardbased microbicides in vivo despite variable in vitro activity. PLoS One. 2008;3(9):e3162.

16. Kilmarx PH, Blanchard $\mathrm{K}$, Chaikummao S, et al. A randomized, placebo-controlled trial to assess the safety and acceptability of use of carraguard vaginal gel by heterosexual couples in Thailand. Sex Transm Dis. 2008;35(3):226-232.

17. Girond S, Crance JM, van Cuyck-Gandre H, Renaudet J, Deloince R. Antiviral activity of carrageenan on hepatitis A virus replication in cell culture. Res Virol. 1991;142(4):261-270.

18. Damonte EB, Matulewicz MC, Cerezo AS. Sulfated seaweed polysaccharides as antiviral agents. Curr Med Chem. 2004;11(18):2399-2419.

19. Ghosh T, Chattopadhyay K, Marschall M, Karmakar P, Mandal P, Ray B. Focus on antivirally active sulfated polysaccharides: from structureactivity analysis to clinical evaluation. Glycobiology. 2009;19(1):2-15.

20. Witvrouw M, De Clercq E. Sulfated polysaccharides extracted from sea algae as potential antiviral drugs. Gen Pharmacol. 1997;29(4):497-511.

21. Grassauer A, Weinmuellner R, Meier C, Pretsch A, Prieschl-Grassauer $\mathrm{E}$, Unger H. Iota-carrageenan is a potent inhibitor of rhinovirus infection. Virol J. 2008;5:107.

22. Leibbrandt A, Meier C, König-Schuster M, et al. Iota-carrageenan is a potent inhibitor of influenza A virus infection. PLoS One. 2010;5(12): e14320.

23. Eccles R, Meier C, Jawad M, Weinmüllner R, Grassauer A, PrieschlGrassauer E. Efficacy and safety of an antiviral iota-carrageenan nasal spray: a randomized, double-blind, placebo-controlled exploratory study in volunteers with early symptoms of the common cold. Respir Res. 2010;11:108.

24. Fazekas T, Eickhoff P, Pruckner N, et al. Lessons learned from a doubleblind randomised placebo-controlled study with a iota-carrageenan nasal spray as medical device in children with acute symptoms of common cold. BMC Complement Altern Med. 2012;12:147.

25. Ludwig M, Enzenhofer E, Schneider S, et al. Efficacy of a carrageenan nasal spray in patients with common cold: a randomized controlled trial. Respir Res. 2013;14:124.

26. Koenighofer M, Lion T, Bodenteich A, et al. Carrageenan nasal spray in virus confirmed common cold: individual patient data analysis of two randomized controlled trials. Multidiscip Respir Med. 2014;9(1):57.

27. Morokutti-Kurz M, Graf C, Prieschl-Grassauer E. Amylmetacresol/2,4dichlorobenzyl alcohol, hexylresorcinol, or carrageenan lozenges as active treatments for sore throat. Int J Gen Med. 2017;10:53-60.

28. Greimel A, Bernkop-Schnürch A, Del Curto MD, D’Antonio M. Transport characteristics of a beta sheet breaker peptide across excised bovine nasal mucosa. Drug Dev Ind Pharm. 2007;33(1):71-77.

29. Wilson TD, Steck WF. A modified HET-CAM assay approach to the assessment of anti-irritant properties of plant extracts. Food Chem Toxicol. 2000;38(10):867-872. 
30. Paper DH, Karall E, Kremser M, Krenn L. Comparison of the antiinflammatory effects of Drosera rotundifolia and Drosera madagascariensis in the HET-CAM assay. Phytother Res. 2005;19(4):323-326.

31. Luepke NP. Hen's egg chorioallantoic membrane test for irritation potential. Food Chem Toxicol. 1985;23(2):287-291.

32. Vinardell MP, Macián M. Comparative study of the HET-CAM test and the Draize eye test for assessment of irritancy potential. Toxicol In Vitro. 1994;8(3):467-470.
33. Nichols WG, Peck Campbell AJ, Boeckh M. Respiratory viruses other than influenza virus: impact and therapeutic advances. Clin Microbiol Rev. 2008;21(2):274-290, table of contents.

34. Hebar A, Koller C, Seifert JM, et al. Non-clinical safety evaluation of intranasal iota-carrageenan. PLoS One. 2015;10(4):e0122911.

35. Andersen I, Camner P, Jensen PL, Philipson K, Proctor DF. A comparison of nasal and tracheobronchial clearance. Arch Environ Health. 1974;29(5):290-293.
International Journal of General Medicine

\section{Publish your work in this journal}

The International Journal of General Medicine is an international peer-reviewed open-access journal that focuses on general and internal medicine, pathogenesis, epidemiology, diagnosis, monitoring and treatment protocols. The journal is characterized by the rapid reporting of reviews, original research and clinical studies across all disease areas.

\section{Dovepress}

The manuscript management system is completely online and includes a very quick and fair peer-review system, which is all easy to use. Visit http://www.dovepress.com/testimonials.php to read real quotes from published authors.

Submit your manuscript here: https://www.dovepress.com/international-journal-of-general-medicine-journal 